\title{
Erratum to: On the technical and economic feasibility of a solar thermodynamic power plant in an area of medium-high direct sunlight intensity: an actual case study
}

\author{
Angelo Maiorino $^{1}\left[\right.$ Marta Valentini $^{2}$
}

Published online: 29 August 2016

(C) The Brazilian Society of Mechanical Sciences and Engineering 2016

Erratum to: J Braz. Soc. Mech. Sci. Eng.

DOI 10.1007/s40430-016-0620-9

The original version of this article unfortunately contained a mistake.

The spelling of the second author was incorrect. The correct name is Marta Valentini.

The original article was corrected.

The online version of the original article can be found under doi:10.1007/s40430-016-0620-9.

Angelo Maiorino

amaiorino@unisa.it

1 Department of Industrial Engineering, University of Salerno,

Via Giovanni Paolo II 132, 84084 Fisciano, SA, Italy

2 AXA Assicurazioni, C.so Como 17, 20154 Milan, Italy 